\title{
MAXIMUM SPECIES RICHNESS AT INTERMEDIATE FREQUENCIES OF DISTURBANCE: CONSISTENCY AMONG LEVELS OF PRODUCTIVITY
}

\author{
J. Robin Svensson, ${ }^{1,5}$ Mats Lindegarth, ${ }^{1}$ Michael Siccha,${ }^{2}$ Mark Lenz, ${ }^{3}$ Markus Molis, ${ }^{4}$ Martin Wahl, ${ }^{3}$ \\ and Henrik Pavia ${ }^{1}$ \\ ${ }^{1}$ Department of Marine Ecology, Göteborg University, Tjärnö Marine Biological Laboratory, 45296 Strömstad, Sweden \\ ${ }^{2}$ Institute for Geological Science, Eberhard Karls University Tübingen Sigwartstr.10, 72076 Tübingen, Germany \\ ${ }^{3}$ Leibniz-Institute for Marine Science, Düsternbrooker Weg 20, 24105 Kiel, Germany \\ ${ }^{4}$ Biologische Anstalt Helgoland, Alfred Wegener Institute for Polar and Marine Research, Marine Station, \\ Kurpromenade 201, 27498 Helgoland, Germany
}

\begin{abstract}
Development of a mechanistic understanding and predictions of patterns of biodiversity is a central theme in ecology. One of the most influential theories, the intermediate disturbance hypothesis (IDH), predicts maximum diversity at intermediate levels of disturbance frequency. The dynamic equilibrium model (DEM), an extension of the IDH, predicts that the level of productivity determines at what frequency of disturbance maximum diversity occurs. To test, and contrast, the predictions of these two models, a field experiment on marine hard-substratum assemblages was conducted with seven levels of disturbance frequency and three levels of nutrient availability. Consistent with the IDH, maximum diversity, measured as species richness, was observed at an intermediate frequency of disturbance. Despite documented effects on productivity, the relationship between disturbance and diversity was not altered by the nutrient treatments. Thus, in this system the DEM did not improve the understanding of patterns of diversity compared to the IDH. Furthermore, it is suggested that careful consideration of measurements and practical definitions of productivity in natural assemblages is necessary for a rigorous test of the DEM
\end{abstract}

Key words: competitive exclusion; disturbance; productivity; species richness.

\section{INTRODUCTION}

Spatial and temporal patterns of diversity in natural communities are central themes in classical natural history as well as in contemporary theoretical ecology (e.g., Huston 1994, Hubbell 2001). Throughout history the magnitude of existing biological diversity and its heterogeneous distribution have continuously challenged ecologists to develop and test models to explain patterns at a multitude of temporal and spatial scales, using increasingly more complex models (e.g., Connell 1978, Huston 1994, Hubbell 2001). Some of these models have been based on biological interactions (e.g., Miller 1958, Fischer 1960, Paine 1966, Paine and Vadas 1969, Menge and Sutherland 1987), while others have primarily focused on abiotic processes (e.g., Hutchinson 1961, Levin and Paine 1974, Connell 1978, Paine and Levin 1981).

Many of these ideas rely on disturbances to disrupt the effects of biological interactions, such as competitive exclusion, on diversity. A variety of abiotic (e.g., fire, wind, wave action, and drifting logs) and biotic factors (e.g., grazing, predation, and trampling) may act as agents of disturbance, depending on the specific

Manuscript received 8 June 2006; revised 25 September 2006; accepted 29 September 2006. Corresponding Editor: S. G. Morgan.

${ }^{5}$ E-mail: robin.svensson@tmbl.gu.se properties of the particular ecological system. There is also a range of definitions of what constitutes an actual disturbance. Grime (1977) defined disturbance as partial or total destruction of biomass. Sousa (1984) extended this definition by adding that disturbance also creates opportunities for new individuals to become established. Pickett and White (1985) have a broader definition where disturbance is "... any relative discrete event in time that disrupts ecosystems, community, or population structure and changes resources, substrate availability, or the physical environment." Thus, despite some ambiguity in the definition of the concept of disturbance, it has direct effects on vital rates and population dynamics and it is therefore a potentially useful generalization.

One important conceptual formulation of the effects of natural disturbances on diversity is the intermediate disturbance hypothesis, IDH (Connell 1978). The IDH predicts that diversity will be large at intermediate rates of disturbance and smaller at higher and lower rates of disturbance. The rationale for this idea is that at low rates of disturbance strong competitors exclude competitively inferior species and communities are dominated by a few species. Intermediate rates of disturbance, however, disrupt competitive hierarchies by increasing rates of mortality and thus making free space available for recruitment of competitively inferior species. At successively higher rates of disturbance, recruitment 
cannot balance the high rates of mortality, and slowrecruiting species disappear from the community. Findings consistent with the predictions of the IDH have been made in manipulative studies in both terrestrial (e.g., Molino and Sabatier 2001, Anderson et al. 2005) and marine (e.g., Osman 1977, Sousa 1979, Valdivia et al. 2005, Patricio et al. 2006) ecosystems. However, contradictory observations have also been made (Lake et al. 1989, Collins et al. 1995, Gutt and Piepenburg 2003), and due to difficulties of incorporating all components of natural environments, laboratory studies are often relatively less supportive (Cowie et al. 2000). In summary, the IDH has been an influential concept in research and also as a tool in management of nature reserves (Wootton 1998).

In response to observations that did not appear consistent with the IDH, Huston (1979) suggested that the relationship between disturbance and diversity is modified by the level of productivity. Using a dynamic equilibrium model (DEM), Huston (1979, later elaborated by Kondoh 2001) suggested that increased productivity, and thus growth rates of individuals and populations, means that a more severe disturbance is required to prevent competitive exclusion. As a consequence, maximum diversity is observed at lower intensities of disturbance when productivity is low, compared to when productivity is high. The shape of the relationship between disturbance and diversity may therefore be of three general types: monotonically decreasing (at low productivity), unimodal (when productivity is intermediate), and monotonically increasing (when productivity is high). These three types of relationships have been observed in various habitats (e.g., Mackey and Currie 2001), but evidence from explicit manipulative studies demonstrating the interactive effects of disturbance and productivity is scarce (Rashit and Bazin 1987, Widdicombe and Austen 2001). One pioneering test in marine rocky environments is the study by Worm et al. (2002), who observed interactive effects of nutrient enrichment and disturbance (grazing by mesoherbivores) on algal diversity, which they found consistent with those predicted by the DEM.

The development from a simple general model involving only one factor, into a more complex and detailed model involving multiple factors, may represent important conceptual progress within a field of research (e.g., Hilborn and Mangel 1997, Underwood 1997). The benefit of a more complex model is that it may be used to accurately predict a more diverse set of conditions with little discrepancy due to approximation (Zucchini 2000). There are, however, no guarantees that a complex model is more powerful than a simple one (e.g., Zucchini 2000, Ginzburg and Jensen 2004). This is because a complex model has a greater uncertainty, as it requires more parameters to be estimated. Thus, in terms of predictive power, the utility of a complex model relies on whether the reduction of error due to approximation is larger than the increase in error due to estimation.
Indeed, from observational data it appears that the great range of observed responses of diversity to disturbance (Mackey and Currie 2001) can potentially be more accurately represented if productivity is included (Huston 1979). Whether this really is the case in a wide range of ecological systems remains to be tested in manipulative experiments.

In this study we contrast predictions from the IDH to those of the DEM in a marine hard-substratum community. Physical disturbance and nutrient availability were manipulated in subtidal communities in the field, with seven distinct frequencies of disturbance and three levels of nutrient availability. Manipulative studies on epibenthic assemblages have made important contributions to the development and testing of general ecological models (e.g., Paine 1966, Dayton 1971, Lubchenco and Menge 1978, Sousa 1979). Due to their potential for quick recovery, epibenthic assemblages have proven particularly useful for investigating disturbance-diversity patterns over ecologically relevant time scales in manipulative studies (e.g., Worm et al. 2002, Bertocci et al. 2005, Jara et al. 2006).

\section{Materials And Methods}

Study site

The field experiment was conducted in the vicinity of Tjärnö Marine Biological Laboratory on the west coast of Sweden. The experimental sites were two bays located $\sim 1 \mathrm{~km}$ apart $\left(58^{\circ} 52.92^{\prime} \mathrm{N}, 11^{\circ} 8.31^{\prime} \mathrm{E}\right.$ and $58^{\circ} 52.17^{\prime} \mathrm{N}$; $11^{\circ} 8.82^{\prime} \mathrm{E}$ for sites 1 and 2, respectively). Site 1 has an average depth of $8 \mathrm{~m}$ and is surrounded by muddy and rocky shores. The surrounding cliffs were covered with red, green, and brown macroalgae as well as mussels and tunicates. Site 2 has an average depth of $6 \mathrm{~m}$ and is surrounded by sandy beaches and boulder fields. Site 2 also has an extensive Zostera meadow and the boulders were commonly overgrown by fucoids, barnacles, and mussels. The grazers in this system are exclusively socalled mesoherbivores, such as amphipods, isopods, and littorinid gastropods (Pavia et al. 1999, Wikstrom et al. 2006). Gastropods were effectively excluded from reaching the panels due to the positioning and construction of the experimental units (see Experimental design), and because of the low abundance of crustacean mesoherbivores in the vicinity of the experimental units, possible effects of grazing are not likely to have affected the results of this study. The waters off the Swedish west coast are generally low in nutrients during the summer months (Nilsson 1991), and nutrients therefore become a limiting resource in this system (Soderstrom 1996).

\section{Experimental design}

Mooring units, made from $2100 \times 250 \times 4 \mathrm{~mm}$ polyvinyl chloride (PVC) strips bent into a ring, were hung from a buoy $\sim 0.5 \mathrm{~m}$ below the water surface. In this way, benthic consumers were excluded from the setup. The rings were deployed on 1 March to allow settling and establishment of communities before the 
experimental manipulation started on 12 May. The experimental manipulation had a duration of 24 weeks and was terminated on 27 October 2004.

On each ring $10 \mathrm{PVC}$ panels $(150 \times 150 \times 3 \mathrm{~mm})$, roughened with emery paper, were attached with cable ties. The panels were randomly allocated to combinations of seven disturbance levels and three nutrient levels. Disturbance treatments consisted of a manual removal of biomass from two randomly selected nonoverlapping areas, each covering $10 \%$ of the panel area, at each disturbance event. The scraping not only kills or damages individuals, but also facilitates recruitment by the freed substratum, and the disturbance is therefore coherent with the definition by Sousa (1984). This disturbance was applied at six different frequencies: every second, fourth, sixth, eighth, 10th, and 12th week (treatments D1-D6), or left undisturbed (treatment D0). Treatments D0-D6 were present in all rings, with two replicates of D0 on each ring, and the remaining two panels were randomly assigned disturbance treatments to allow additional replication within rings.

One of three different levels of nutrient enrichment was applied to each ring by attaching 10 fertilizer bags (1-mm mesh) among the panels. For the highest level of enrichment $\left(\mathrm{N}^{++}\right)$, bags were filled with $100 \mathrm{~g}$ of fertilizer; for the moderately enriched level $\left(\mathrm{N}^{+}\right)$, bags were filled with gravel and $50 \mathrm{~g}$ fertilizer, and bags with ambient nutrient concentration (N0) were filled only with gravel. The slow-release Plantacote Depot 6-M,

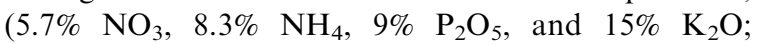
Aglukon, Düsseldorf, Germany) was used as fertilizer due to its steady release rate in relation to mass, where a doubling in mass leads to twice the amount of nutrients being released (Worm et al. 2000). Each level of nutrient availability was replicated on four randomly assigned rings. All bags were placed inside the rings at the start of the experiment and changed every fourth week in order to have constant nutrient release throughout the experiment.

\section{Sampling}

Sampling of abundance of each species and composition of the experimental communities was done before the start of the manipulation and thereafter every eighth week until the termination of the experiment. Data on undisturbed communities obtained from the sampling after eight weeks were used for testing effects of nutrient availability on algal cover. The time of sampling was selected to be early in the growth season to minimize confounding influences of competition. Data from the last sampling after 24 weeks were used for the main analyses, i.e., the tests of the IDH and the DEM, and data on undisturbed communities from all sampling events were used for studying changes in the communities over time. Panels were detached and brought into the laboratory submerged in seawater, kept under running seawater in the laboratory during the entire sampling procedure, and brought back into the field within 16 hours of each sampling event. Before sampling, the back side and edges of all panels were scraped clean and their wet mass was measured. The percentage cover of bare space and sessile species was then estimated in $5 \%$ intervals using a $15 \times 15 \mathrm{~cm}$ plastic grid (mesh size $5 \mathrm{~cm}^{2}$ ). A $1-\mathrm{cm}$ margin to all edges of the panels was not assessed, and the percentage cover of species with a small holdfast and wide thallus was estimated from the two-dimensional projection of the organism on the panel. Sessile epibionts were also accounted for. Thus, total cover was allowed to exceed $100 \%$.

\section{Statistical analyses}

The data on species richness were analyzed with analysis of variance (ANOVA) using Statistica 6.0 (Statsoft Incorporated, Tulsa, Oklahoma, USA). The models were tested, with species richness as a measure of diversity, following the elaboration of the DEM by Kondoh (2001). Hypotheses about effects of main factors and interactions were tested using the following general linear model:

$$
\begin{aligned}
X_{i j k l m}= & \mu+S_{i}+N_{j}+S N_{i j}+D_{k}+S D_{i k}+N D_{j k}+S N D_{i j k} \\
& +R(S N)_{l(i j)}+D R(S N)_{k l(i j)}+\varepsilon_{i j k l m}
\end{aligned}
$$

where $\mu$ is the overall mean, site $\left(S_{i}\right)$ is a random factor with two levels, nutrient enrichment $\left(N_{j}\right)$ and disturbance frequency $\left(D_{k}\right)$ are fixed factors with three and seven levels respectively, ring $\left(R[S N]_{l(i j)}\right)$ is a nested random factor with four levels, and $\varepsilon_{i j k l m}$ is a random deviation. Due to loss of one ring and lack of complete replication of all levels of disturbance on each ring, type III sums of squares was used for estimation (Henderson 1953). The residual was estimated from the variability between undisturbed panels and from the additional replicated treatments within each ring. To optimize statistical power of tests, post hoc elimination and pooling of negligible variance components (i.e., if $P>$ 0.25) were performed (Winer et al. 1991, Underwood 1997).

Support for either of the two models, IDH or DEM, is provided by two different terms in the linear model. The IDH is supported if there is a significant effect of disturbance and if the relationship between richness and disturbance is unimodal with an optimum at intermediate levels of disturbance. This is equivalent to the presence of a significant quadratic component in a polynomial regression. In contrast the DEM is supported by a significant interaction between disturbance and nutrient enrichment. The predictions of the DEM then need to be further evaluated using polynomial regression within individual levels of nutrient enrichment.

A fundamental premise for any experimental support for the DEM is that the nutrient treatments actually cause an increased primary productivity. In order to detect effects on productivity as a consequence of the nutrient treatment, differences in cover of macroalgae 
TABLE 1. Abundance (mean percent cover $\pm \mathrm{SE}$ ) of sessile invertebrate and algal species present in the experimental communities from both sites after 24 weeks, averaged over nutrient treatment for all levels of disturbance (D0-D6).

\begin{tabular}{|c|c|c|c|c|c|c|c|}
\hline Taxon & D0 & D1 & D2 & D3 & D4 & D5 & D6 \\
\hline \multicolumn{8}{|l|}{ Chlorophyceae } \\
\hline $\begin{array}{l}\text { Ulva intestinalis } \\
\text { Ulva lactuca }\end{array}$ & $0.09 \pm 0.04$ & $0.10 \pm 0.06$ & $0.10 \pm 0.06$ & $\begin{array}{l}0.39 \pm 0.19 \\
0.04 \pm 0.04\end{array}$ & $0.06 \pm 0.04$ & $\begin{array}{l}0 \\
0\end{array}$ & $0.17 \pm 0.14$ \\
\hline \multicolumn{8}{|l|}{ Phaeophyceae } \\
\hline Ectocarpus siliculosus & $0.45 \pm 0.26$ & $0.03 \pm 0.03$ & $0.59 \pm 0.29$ & $0.11 \pm 0.06$ & $0.11 \pm 0.05$ & $0.18 \pm 0.16$ & $0.20 \pm 0.15$ \\
\hline \multicolumn{8}{|l|}{ Rhodophyceae } \\
\hline $\begin{array}{l}\text { Bonnemaisonia hamifera } \\
\text { Ceramium rubrum } \\
\text { Ceramium strictum } \\
\text { Dasya baillouviana } \\
\text { Osmundea truncata } \\
\text { Polysiphonia fucoides } \\
\text { Polysiphonia urceolata } \\
\text { Spermothamnion repens }\end{array}$ & $\begin{array}{c}0 \\
1.98 \pm 0.57 \\
0.07 \pm 0.04 \\
0.04 \pm 0.03 \\
0 \\
0.83 \pm 0.49 \\
0 \\
0.20 \pm 0.12\end{array}$ & $\begin{array}{c}0 \\
2.62 \pm 0.53 \\
0.07 \pm 0.05 \\
0.03 \pm 0.03 \\
0.03 \pm 0.03 \\
0.17 \pm 0.07 \\
0 \\
0.07 \pm 0.05\end{array}$ & $\begin{array}{c}0 \\
4.21 \pm 1.06 \\
0.03 \pm 0.03 \\
0.03 \pm 0.03 \\
0 \\
0.38 \pm 0.18 \\
0.03 \pm 0.03 \\
0.03 \pm 0.03\end{array}$ & $\begin{array}{c}0 \\
3.39 \pm 1.07 \\
0.07 \pm 0.05 \\
0.04 \pm 0.04 \\
0 \\
0.61 \pm 0.36 \\
0.21 \pm 0.18 \\
0.25 \pm 0.18\end{array}$ & $\begin{array}{c}0 \\
2.23 \pm 0.55 \\
0.03 \pm 0.03 \\
0.03 \pm 0.03 \\
0.06 \pm 0.04 \\
1.46 \pm 1.15 \\
0 \\
0.23 \pm 0.15\end{array}$ & $\begin{array}{l}0.04 \pm 0.03 \\
0.64 \pm 0.17 \\
0.14 \pm 0.06 \\
0.04 \pm 0.03 \\
0 \\
0.21 \pm 0.07 \\
0 \\
0.38 \pm 0.17\end{array}$ & $\begin{array}{c}0 \\
2.09 \pm 1.07 \\
0.03 \pm 0.03 \\
0.17 \pm 0.14 \\
0.03 \pm 0.03 \\
0.40 \pm 0.29 \\
0 \\
0.09 \pm 0.05\end{array}$ \\
\hline \multicolumn{8}{|l|}{ Porifera } \\
\hline Leucosolenia botryoides & $0.78 \pm 0.28$ & $1.28 \pm 0.50$ & $1.10 \pm 0.43$ & $1.21 \pm 0.53$ & $1.40 \pm 0.49$ & $1.36 \pm 0.43$ & $0.74 \pm 0.24$ \\
\hline \multicolumn{8}{|l|}{ Cnidaria } \\
\hline $\begin{array}{l}\text { Clytia hemispherica } \\
\text { Laomedea flexuosa } \\
\text { Metridium senile } \\
\text { Sargatiogeton undatus }\end{array}$ & $\begin{array}{c}0 \\
12.8 \pm 2.30 \\
0.11 \pm 0.05 \\
0.07 \pm 0.04\end{array}$ & $\begin{array}{c}0 \\
18.9 \pm 3.09 \\
0.14 \pm 0.06 \\
0.14 \pm 0.06\end{array}$ & $\begin{array}{c}0 \\
19.7 \pm 3.07 \\
0.31 \pm 0.18 \\
0.03 \pm 0.03\end{array}$ & $\begin{array}{l}0.04 \pm 0.04 \\
23.9 \pm 4.30 \\
0.39 \pm 0.36 \\
0.18 \pm 0.07\end{array}$ & $\begin{array}{c}0 \\
19.9 \pm 3.04 \\
0.14 \pm 0.06 \\
0.11 \pm 0.05\end{array}$ & $\begin{array}{c}0 \\
30.7 \pm 3.44 \\
0.14 \pm 0.06 \\
0.14 \pm 0.06\end{array}$ & $\begin{array}{c}0 \\
24.4 \pm 2.44 \\
0.37 \pm 0.20 \\
0.06 \pm 0.04\end{array}$ \\
\hline \multicolumn{7}{|l|}{ Annelida } & $0.49 \pm 0.09$ \\
\hline \multicolumn{8}{|l|}{ Crustacea } \\
\hline $\begin{array}{l}\text { Mollusca } \\
\text { Mytilus edulis } \\
\text { Podesmus sp. }\end{array}$ & $0.35 \pm 0.12$ & $\begin{array}{l}0.52 \pm 0.18 \\
0.17 \pm 0.17\end{array}$ & $0.59 \pm 0.24$ & $0.64 \pm 0.25$ & $0.63 \pm 0.24$ & $\begin{array}{l}1.00 \pm 0.37 \\
0.04 \pm 0.03\end{array}$ & $0.57 \pm 0.29$ \\
\hline \multicolumn{8}{|l|}{ Bryozoa } \\
\hline $\begin{array}{l}\text { Cryptosula pallasiana } \\
\text { Electra pilosa } \\
\text { Membranipora membranacea }\end{array}$ & $\begin{array}{l}0.39 \pm 0.19 \\
0.91 \pm 0.29 \\
0.33 \pm 0.19\end{array}$ & $\begin{array}{l}0.28 \pm 0.18 \\
1.34 \pm 0.46 \\
0.03 \pm 0.03\end{array}$ & $\begin{array}{c}0.03 \pm 0.03 \\
0.76 \pm 0.28 \\
0\end{array}$ & $\begin{array}{l}0.04 \pm 0.04 \\
0.93 \pm 0.33 \\
0.71 \pm 0.42\end{array}$ & $\begin{array}{l}0.23 \pm 0.15 \\
0.46 \pm 0.20 \\
0.14 \pm 0.14\end{array}$ & $\begin{array}{l}0.29 \pm 0.16 \\
1.36 \pm 0.34 \\
0.18 \pm 0.16\end{array}$ & $\begin{array}{l}0.06 \pm 0.04 \\
0.49 \pm 0.20 \\
0\end{array}$ \\
\hline \multicolumn{8}{|l|}{ Hemichordata } \\
\hline $\begin{array}{l}\text { Ascidiella aspersa } \\
\text { Botryllus schlosseri } \\
\text { Botrylloides leachi } \\
\text { Ciona intestinalis }\end{array}$ & $\begin{array}{c}11.9 \pm 2.38 \\
0 \\
0 \\
84.0 \pm 3.50\end{array}$ & $\begin{array}{c}12.3 \pm 2.74 \\
0 \\
0 \\
75.3 \pm 5.15\end{array}$ & $\begin{array}{c}12.5 \pm 2.27 \\
0 \\
0.17 \pm 0.17 \\
64.3 \pm 5.17\end{array}$ & $\begin{array}{c}8.32 \pm 2.13 \\
0.04 \pm 0.04 \\
0 \\
71.4 \pm 4.82\end{array}$ & $\begin{array}{c}8.94 \pm 1.81 \\
0 \\
0 \\
68.0 \pm 4.69\end{array}$ & $\begin{array}{c}8.82 \pm 1.60 \\
0 \\
0 \\
53.6 \pm 4.04\end{array}$ & $\begin{array}{c}5.03 \pm 1.17 \\
0 \\
0 \\
17.3 \pm 2.25\end{array}$ \\
\hline
\end{tabular}

among levels of enrichment were tested using undisturbed panels (D0) after eight weeks. Data were analyzed using ANOVA:

$$
X_{i j k}=\mu+S_{i}+N_{j}+S N_{i j}+R(S N)_{k(i j)}+\varepsilon_{i j k}
$$

\section{RESUlTS}

\section{General observations}

During the experiment a total of 15 species of algae and 17 species of sessile invertebrates were observed. The most abundant organisms, occupying large areas of the panels, were the tunicates Ciona intestinalis and Ascidiella aspersa and the hydroid Laomedea flexuosa. At the end of the experiment, ephemeral algae, bryozoans, and sea anemones were frequent in the communities, although usually low in cover (Table 1). Studies of the development of undisturbed communities showed that richness was highest after 8 weeks at site 1 and after 16 weeks at site 2 (Fig. 1A). The decrease in richness at later stages suggests that some species were excluded as a result of competition. This is consistent with the observation of an earlier peak in richness at site 1, following the establishment of a dense cover of $C$. intestinalis at this site (Fig. 1B). The ascidians occupied $>95 \%$ of the space on control panels after 24 weeks at site 1 , suggesting that $C$. intestinalis is a competitive dominant in this system, capable of excluding both other invertebrates as well as most species of macroalgae (Fig. $1 \mathrm{~B})$.

\section{Assessment of productivity}

The analysis of algal cover in undisturbed communities after 8 weeks showed that there was a statistically significant response to increased nutrient availability $\left(F_{2,44}=10.74, P<0.001\right)$. Inspection of means (mean [ $\pm \mathrm{SE}$ ] cover of algae for $\mathrm{N} 0, \mathrm{~N}^{+}$, and $\mathrm{N}^{++}$were $54.5 \pm$ 

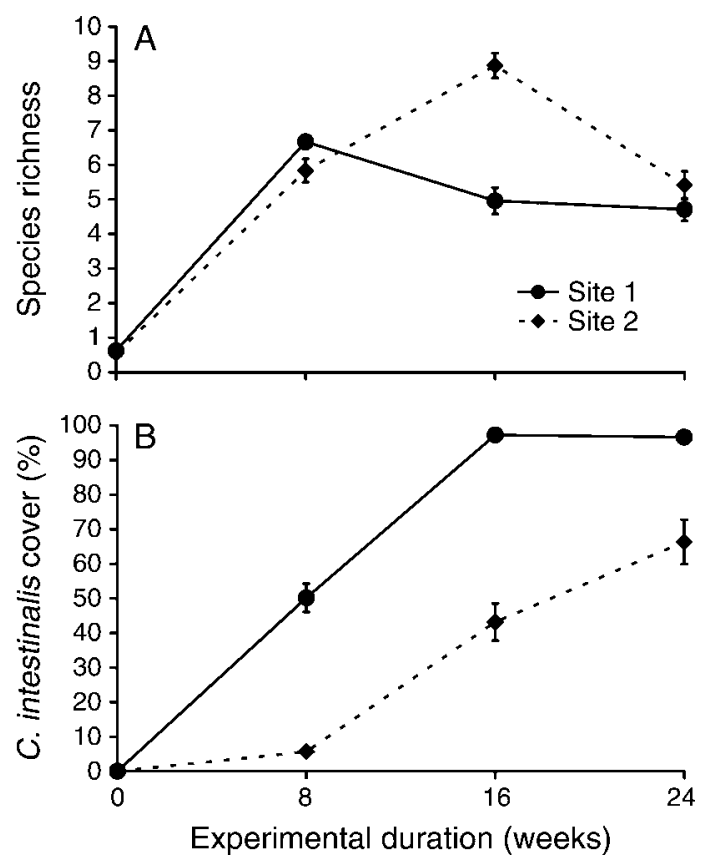

FIG. 1. Temporal patterns of (A) species richness and (B) percent cover of $C$. intestinalis in fouling communities at sites 1 and 2. Data are presented as mean $\pm \mathrm{SE}$.

$5.13 \%, 82.5 \pm 4.41 \%$, and $71.1 \pm 3.55 \%$, respectively) and the SNK test revealed that there were significant differences between unfertilized panels (N0) and those fertilized $\left(\mathrm{N}^{+}\right.$and $\left.\mathrm{N}^{++}\right)$. Furthermore, there was no significant interaction term between the two factors, site $(S)$ and nutrient enrichment $(N)\left(F_{2,42}=1.45, P=0.25\right)$, suggesting that nutrient availability had a general effect on productivity and that useful tests of the DEM were in fact possible. However, no significant difference in algal cover was observed between $\mathrm{N}^{+}$and $\mathrm{N}^{++}$, which could be due to a saturation of nutrients already at the $\mathrm{N}^{+}$level.

\section{Testing predictions from the IDH and DEM}

Analysis of species richness at the end of the experiment showed that there was a significant effect of disturbance, but no interactive effect of disturbance and nutrients (Table 2a). In all levels of nutrients, there was a tendency for maximum richness at intermediate levels of disturbance (Fig. 2). Initially it might appear that maximum diversity occurred at different levels of disturbance, but the variability among and within levels of disturbance was large and the predicted shift toward more frequent disturbances was not observed (maximum richness was observed at D5, D5, and D2 for N0, $\mathrm{N}^{+}$, and $\mathrm{N}^{++}$, respectively). Considering the fact that the hypothesis about simple effects of disturbance and that of interactive effects involving disturbance and nutrients were both tested using the same pooled mean square as the error term (with $189 \mathrm{df}$ ), conclusions about lack of interactive effects appear robust and not caused by a lack of statistical power. This view is supported by calculation of effect-sizes from estimated mean squares, which reveal that the effect of disturbance was $\sim 20$ times larger than that of the interaction $\left(k_{D}^{2}=1.82\right.$ and $\left.\mathrm{k}_{N \times D}^{2}=0.10\right)$. There was no significant interaction involving disturbance and any of the spatial scales, i.e., sites and rings (Table 2a). This indicates that the effect of disturbance was consistent among places. Nevertheless, significant variability among rings indicates that there was small-scale variability in richness within sites.

Further analysis showed that, not only were there differences among levels of disturbance, but there was also a significant quadratic component in the polynomial regression (Table $2 b$ ), i.e., maximum richness at intermediate disturbances (Fig. 3A). Consistent with the IDH, these results suggest that sessile species are removed at low and high frequencies of disturbance. Inspection of the mean cover of the most abundant taxa suggests that they differ in their responses to disturbance

TABLE 2. (a) ANOVA on species richness at the end of the experiment and (b) regression analysis.

\begin{tabular}{|c|c|c|c|c|c|c|}
\hline Source & df & MS & $F$ & $P$ & Error term & $\overline{R^{2}}$ \\
\hline \multicolumn{7}{|c|}{ a) ANOVA on species richness } \\
\hline Site, $S$ & 1 & 7.47 & 0.94 & 0.34 & $R(S \times N)$ & \\
\hline Nutrients, $N$ & 2 & 2.66 & 0.69 & 0.59 & $S \times N$ & \\
\hline Disturbance, $D$ & 6 & 7.98 & 3.16 & 0.01 & pooled & \\
\hline$S \times N$ & 2 & 3.88 & 0.49 & 0.62 & $R(S \times N)$ & \\
\hline$S \times D$ & 6 & 3.01 & 1.10 & 0.37 & $D \times R(S \times N)$ & \\
\hline$N \times D$ & 12 & 2.58 & 1.03 & 0.43 & pooled & \\
\hline Ring, $R(S \times N)$ & 17 & 7.90 & 3.24 & 0.00 & residual & \\
\hline$S \times N \times D$ & 12 & 0.90 & 0.33 & 0.98 & $D \times R(S \times N)$ & \\
\hline$D \times R(S \times N)$ & 102 & 2.75 & 1.13 & 0.30 & residual & \\
\hline Residual & 69 & 2.44 & & & & \\
\hline Pooled & 189 & 2.53 & & & & \\
\hline \multicolumn{7}{|c|}{ b) Regression analysis $\dagger$} \\
\hline Regression & 2 & 0.44 & 10.04 & 0.03 & & 0.83 \\
\hline Residual & 4 & 0.04 & & & & \\
\hline
\end{tabular}




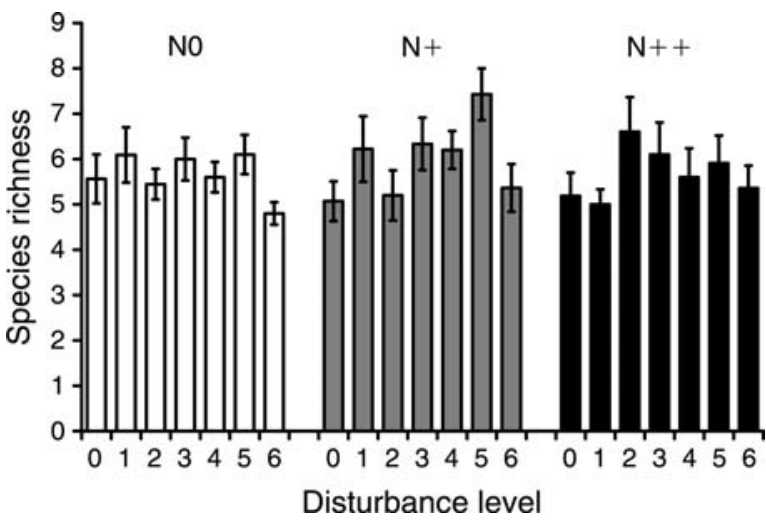

FIG. 2. Effects of disturbance on species richness at different nutrient levels (see Materials and Methods: Experimental design). Data are presented as mean $\pm \mathrm{SE}$.

(Fig. 3B). Thus there is a strong negative effect on the cover of the dominant tunicates Ciona intestinalis and Ascidiella aspersa, while a rapid colonizer such as the hydroid Laomedea flexuosa is positively affected by disturbance.

\section{Discussion}

In this study we found empirical evidence supporting the IDH, but not the DEM. Species richness was highest at an intermediate frequency of disturbance, and this pattern was not significantly affected by different levels of nutrient enrichment. This was in spite of the fact that the nutrient treatment had a significant effect increasing percentage cover of macroalgae, which is closely linked to productivity (Death 2002). In contrast to the IDH, the empirical support for the DEM is scarce. So far support has come from observational studies of flooding in riparian wetlands (Pollock et al. 1998), a mesocosm study of sediment movement and organic enrichment in deep-sea benthos (Widdicombe and Austen 2001), laboratory experiments of energy availability and mortality in microcosms (Rashit and Bazin 1987), and in the only two experiments that have manipulated disturbance and productivity simultaneously in the field (Worm et al. 2002, Jara et al. 2006). The conclusions from our experiment differ from the few previous studies testing the DEM. Because productivity was manipulated using the same procedures as in Worm et al. (2002) and Jara et al. (2006), the nutrient treatment cannot explain the different results. Instead, it is more likely that the divergent outcomes were caused by differences in (1) the composition of the experimental communities, and/or (2) the way the communities were disturbed.

The communities in this study were not only rich in species, but also in terms of higher taxa and functional groups. During the experiment $>30$ different species were observed in the communities, 15 species of macroalgae and 17 species from such different taxonomic groups as tunicates, mussels, hydroids, bryozoans, barnacles, annelids, and sea anemones. Other experi- ments on the DEM have used more restricted taxon sampling and studied communities composed mainly of algae (Worm et al. 2002), polychaetes (Widdicombe and Austen 2001), protist bacterivores (Scholes et al. 2005), and bacteria, flagellates, and ciliates (Rashit and Bazin 1987). Experiments conducted in more diverse systems can be advantageous due to the possibility of recognizing patterns among more distantly related taxa. In this experiment tunicates occupied most of the space on control panels, and were thus capable of excluding a variety of both invertebrate and macroalgal species. Had the hypotheses been tested in assemblages of solely macroalgae or invertebrates, this dominance of one taxon over several taxa from distant groups might not have been revealed, and patterns among, for instance, only macroalgae (cf. Worm et al. 2002) might have been different and not representative for the natural diversity of hard-substratum assemblages of temperate marine waters. Because the DEM and the IDH are general ecological models intended to explain gradients of diversity in nature, their generality and explanatory power should be assessed using natural communities. The diversity and composition of communities can influence the outcome of an experiment, because different species and functional groups respond differently to experimental treatments. It is therefore impor-
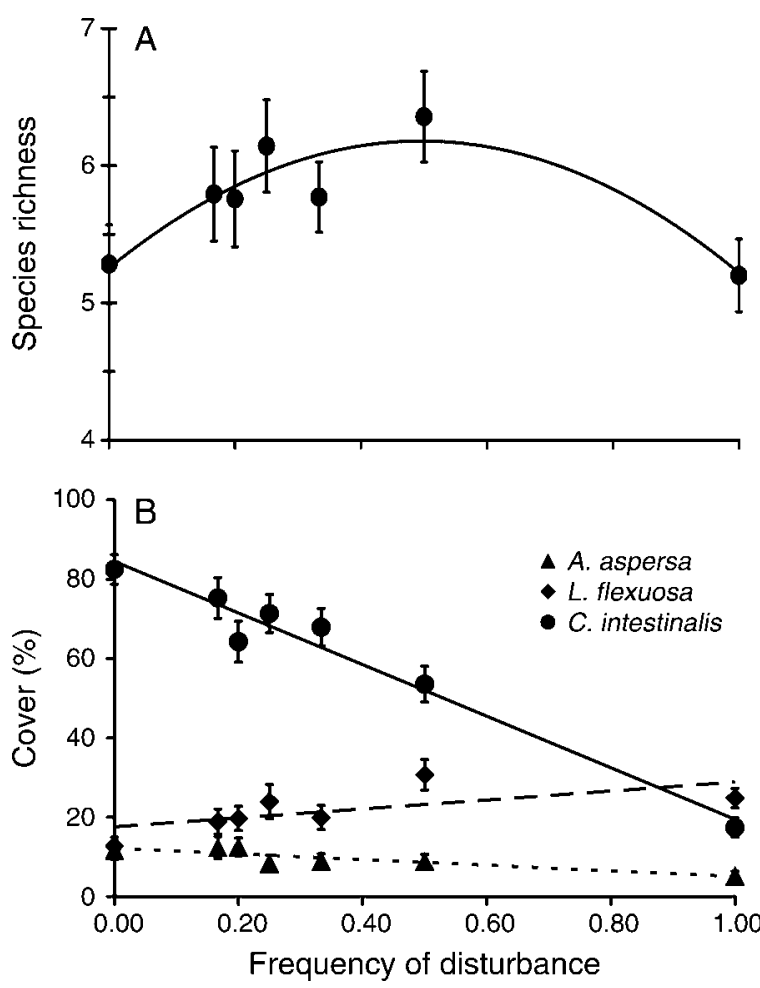

FIG. 3. (A) Species richness on the experimental panels, and (B) percent cover of Ascidiella aspersa, Laomedea flexuosa, and Ciona intestinalis, as functions of relative disturbance frequency (see Materials and Methods: Experimental design). Data are presented as mean $\pm \mathrm{SE}$. 
tant also to consider the composition of communities, and not only the design of experimental treatments, when comparing results and conclusions from experiments on effects of disturbance and productivity on diversity.

Another potential explanation of the difference in results and conclusions between this study and previous studies on the DEM is based on the application and the definition of disturbance. In this study we used controlled levels of mechanical scraping. This type of disturbance shares important properties with natural disturbances, such as ice-scouring (Åberg 1992), drifting logs (Dayton 1971), and wave action (Dudgeon et al. 1999), in the sense that it makes free space available for settling (i.e., the limiting resource). This is a central component in definitions of disturbance (Sousa 1984, 2001), which is not always considered in experimental manipulations (e.g., Rashit and Bazin 1987, Scholes et al. 2005). Another potentially complicating issue is the selectivity of agents of disturbance in manipulative experiments. Worm et al. (2002) used mesoherbivores as agents of disturbance in communities composed largely of macroalgae. In this case it is possible that interactions, not predicted by the DEM, occurred between grazing and nutrient enrichment of algae. Grazers have been shown to prefer plants (Onuf et al. 1977) and macroalgae (Cruz-Rivera and Hay 2000) with higher nutrient content, whereas physical disturbance has no such selectivity. Grazing has previously been argued as an unsuitable agent of disturbance in studies on the IDH (e.g., McGuinness 1987, Sousa 2001). Due to selective preference for nutrient-rich individuals, grazing might be an even less appropriate agent of disturbance in studies on the DEM.

Despite its conceptual appeal, the scarcity of manipulative studies suggests that empirical testing of the DEM may not be straightforward. One important issue that has to be considered in experimental tests of the DEM is that the extensive discussion about agents and definitions of disturbance (Grime 1977, Pickett and White 1985, Sousa 2001) has no equivalence for productivity. Experimental manipulation of productivity is often done indirectly, i.e., by adding nutrients. This has two fundamental implications for the interpretation of manipulative experiments. First, it becomes necessary to test not only for effects of the experimental treatment on diversity, but also to test independently whether the actual experimental treatment (the adding of nutrients) has an effect on productivity. Without evidence for an actual increase in productivity, it is not clear whether the experiment is testing the DEM or not. Unfortunately, this is not always made clear (e.g., Widdicombe and Austen 2001, Scholes et al. 2005, Jara et al. 2006). Another problematic issue is the fact that productivity of an assemblage is determined both by external factors (i.e., light, temperature, energy transport, and nutrients) and internal processes (i.e., differences in usage of resources, resource capture ability, and energy conver- sion ability within and among species [Tilman 1980, Tilman and Pacala 1993]). In a field experiment on natural assemblages, energy conversion ability is usually not amenable to manipulation. One consequence is that there may be a lack of independence between the response variable and the levels of the experimental factor. This is because the productivity of an assemblage may influence diversity (e.g., Connell and Orias 1964, Abrams 1995) at the same time as the diversity influences the productivity (e.g., Tilman et al. 1996). Therefore, in an experiment where productivity is manipulated indirectly, the response variable (i.e., some measure of diversity) may modify the effect of the experimental treatment. This relationship may lead to confusion about cause and effect in otherwise carefully planned experiments. Nevertheless, if predictions about effects of productivity on diversity are to be tested in field experiments, indirect manipulations may be the only conceivable solution. In this system, addition of nutrients, which are often a limiting resource, is probably the most effective way to increase productivity in a field experiment (e.g., Widdicombe and Austen 2001, Worm et al. 2002, Jara et al. 2006).

In a manner similar to manipulations of disturbance, the experimental manipulations of productivity in natural communities are often selective. The matter of selectivity is probably of greater concern in experimental manipulations of productivity, because designing a nonselective agent of productivity is more complicated then designing a nonselective agent of disturbance. If all organisms are affected equally by the productivity treatment, or if the dominant organisms are affected relatively more strongly, it would require a stronger disturbance to prevent competitive exclusion, as predicted by the DEM. However, if the inferior competitors are more strongly affected by the productivity treatment, this could instead slow down the process of competitive exclusion, which would cause diversity to peak at lower intensities of disturbance, rather than at the predicted higher intensities. In this experiment, the dominant tunicates, unlike the ephemeral macroalgae, did not noticeably increase their growth rates in response to the nutrient treatment. This result could explain why an interaction between disturbance and productivity was not found. Jara et al. (2006) also discussed the nutrient treatment as a possible cause for their weak support for the DEM, because the nutrients may only have affected the autotrophic part of the community. Studies that have found the predicted interaction between disturbance and productivity have predominantly been made in plant communities (Pollock et al. 1998, Death 2002) or algae (Worm et al. 2002). In such experiments, the species in the communities would be more equally affected, even though individual species of plants and algae differ in their ability to utilize available resources.

In this study, we found maximum richness at intermediate frequencies of disturbance, which is in 
accordance with the IDH. A literature review showed that this is not a universal pattern in experimental tests of effects of disturbance on diversity (Mackey and Currie 2001). Less than $20 \%$ of the published studies on disturbance-diversity relations supported the IDH. As an extended theory, the DEM may explain some of the results that are inconsistent with the IDH; and it has therefore been suggested that it is preferable to the IDH (Stallins 2003). In their review, Mackey and Currie (2001) found that $>50 \%$ of all experiments on disturbance showed either monotonically positive or negative patterns with increasing disturbance. These patterns could in principle be explained by the DEM, if it could be shown that productivity was high in cases where diversity increased with disturbance, and low when diversity decreased with disturbance. The explanatory power of the DEM is therefore potentially large. Nevertheless, many alternative explanations may be proposed for results that are inconsistent with the IDH. Several authors have suggested that the predictions of the IDH rely on a number of prerequisites, such as competitive exclusion (Connell 1978), large regional species pool (Osman 1977), multiple stages in succession (Collins and Glenn 1997), and trade-off between competition and tolerance (Dial and Roughgarden 1998) and between competition and colonization (Petraitis et al. 1989). Menge and Sutherland (1987) argued that the effects of disturbance depend on the amount of environmental stress in the system. Accordingly, experiments in systems where these prerequisites are not fulfilled seldom find support for the IDH. For instance Cowie et al. (2000) and Huxham et al. (2000) did not observe maximum diversity at intermediate levels of disturbance, because settling propagules and a small regional species pool were lacking. Studies testing the DEM have also explained lack of support for the model with the failure of fulfilment of these requirements. Scholes et al. (2005) suggested that the absence of recolonization of bacteria and ciliates could explain lack of support in the closed microcosms, while Death (2002) found that the DEM could not predict patterns of diversity in forest streams because such systems are not driven by competition. These results imply that models incorporating productivity is only one of several possibilities for improving our understanding of mechanisms behind patterns of diversity. Furthermore, the predictive power and general applicability of the DEM needs to be assessed by further experiments in natural assemblages, where the definition and the ecological relevance of disturbance and productivity treatments are explicitly considered.

\section{ACKNOWLEDGMENTS}

This work was funded by Formas through contract 21.0/2004-0550 to H. Pavia and by Stiftung Mercator through a grant to M. Wahl. Fertilizer was provided by Aglukon, Düsseldorf, Germany. We thank Anneli Lindgren and Elisabet Brock for assistance with identifying species of macroalgae; without their help it would not have been possible to do this project. We also thank R. T. Paine and one anonymous reviewer, whose comments greatly improved an earlier version of the manuscript.

\section{Literature Cited}

Åberg, P. 1992. A demographic study of two populations of the seaweed Ascophyllum nodosum. Ecology 73:1473-1487.

Abrams, P. A. 1995. Monotonic or unimodal diversityproductivity gradients. What does competition theory predict? Ecology 76:2019-2027.

Anderson, R. C., D. Nelson, M. R. Anderson, and M. A. Rickey. 2005. White-tailed deer (Odocoileus virginianus Zimmermann) browsing effects on tallgrass prairie forbs: diversity and species abundances. Natural Areas Journal 25: $19-25$.

Bertocci, I., E. Maggi, S. Vaselli, and L. Benedetti-Cecchi. 2005. Contrasting effects of mean intensity and temporal variation of disturbance on a rocky seashore. Ecology 86:2061-2067.

Collins, S. L., and S. M. Glenn. 1997. Intermediate disturbance and its relationship to within- and between-patch dynamics. New Zealand Journal of Ecology 21:103-110.

Collins, S. L., S. M. Glenn, and D. J. Gibson. 1995. Experimental analysis of intermediate disturbance and initial floristic composition - decoupling cause and effect. Ecology 76:486-492.

Connell, J. H. 1978. Diversity in tropical rain forests and coral reefs. Science 199:1302-1310.

Connell, J. H., and E. Orias. 1964. The ecological regulation of species diversity. American Naturalist 98:399-414.

Cowie, P. R., S. Widdicombe, and M. C. Austen. 2000. Effects of physical disturbance on an estuarine intertidal community: field and mesocosm results compared. Marine Biology 136: 485-495.

Cruz-Rivera, E., and M. E. Hay. 2000. The effects of diet mixing on consumer fitness: macroalgae, epiphytes, and animal matter as food for marine amphipods. Oecologia 123: 252-264.

Dayton, P. K. 1971. Competition, disturbance, and community organization: the provision and subsequent utilization of space in a rocky intertidal community. Ecological Monographs 41:351-389.

Death, R. G. 2002. Predicting invertebrate diversity from disturbance regimes in forest streams. Oikos 97:18-30.

Dial, R., and J. Roughgarden. 1998. Theory of marine communities: the intermediate disturbance hypothesis. Ecology 79:1412-1424.

Dudgeon, S. R., R. S. Steneck, I. R. Davison, and R. L. Vadas. 1999. Coexistence of similar species in a space-limited intertidal zone. Ecological Monographs 69:331-352.

Fischer, A. G. 1960. Latitudinal variations in organic diversity. Evolution 14:64-81.

Ginzburg, L. R., and C. X. J. Jensen. 2004. Rules of thumb for judging ecological theories. Trends in Ecology and Evolution 19:121-126.

Grime, J. P. 1977. Evidence for the existence of three primary strategies in plants and its relevance to ecological and evolutionary theory. American Naturalist 111:1169-1194.

Gutt, J., and D. Piepenburg. 2003. Scale-dependent impact on diversity of Antarctic benthos caused by grounding of icebergs. Marine Ecology Progress Series 253:77-83.

Henderson, C. R. 1953. Estimation of variance and covariance components. Biometrics 9:226-252.

Hilborn, R., and M. Mangel. 1997. The ecological detective. Princeton University Press, Princeton, New Jersey, USA.

Hubbell, S. P. 2001. The unified theory of biodiversity and biogeography. Princeton University Press, Princeton, New Jersey, USA.

Huston, M. A. 1979. A general hypothesis of species diversity. American Naturalist 113:81-101.

Huston, M. A. 1994. Biological diversity: the coexistence of species. Cambridge University Press, Cambridge, UK. 
Hutchinson, G. E. 1961. The paradox of the plankton. American Naturalist 95:137-145.

Huxham, M., I. Roberts, and J. Bremner. 2000. A field test of the intermediate disturbance hypothesis in the soft-bottom intertidal. International Review of Hydrobiology 85:379-394.

Jara, V. C., J. H. S. Miyamoto, B. A. P. da Gama, M. Molis, M. Wahl, and R. C. Pereira. 2006. Limited evidence of interactive disturbance and nutrient effects on the diversity of macrobenthic assemblages. Marine Ecology Progress Series 308:37-48.

Kondoh, M. 2001. Unifying the relationships of species richness to productivity and disturbance. Proceedings of the Royal Society B: Biological Sciences 268:269-271.

Lake, P. S., T. J. Doeg, and R. Marchant. 1989. Effects of multiple disturbance on macroinvertebrate communities in the Acheron River, Victoria. Australian Journal of Ecology 14:507-514.

Levin, S. A., and R. T. Paine. 1974. Disturbance, patch formation, and community structure. Proceedings of the National Academy of Sciences (USA) 71:2744-2747.

Lubchenco, J., and B. A. Menge. 1978. Community development and persistence in a low rocky intertidal zone. Ecological Monographs 48:67-94.

Mackey, R. L., and D. J. Currie. 2001. The diversitydisturbance relationship: is it generally strong and peaked? Ecology 82:3479-3492.

McGuinness, K. A. 1987. Disturbance and organisms on boulders 2. Causes of patterns in diversity and abundance. Oecologia 71:420-430.

Menge, B. A., and J. P. Sutherland. 1987. Community regulation: variation in disturbance, competition, and predation in relation to environmental stress and recruitment. American Naturalist 130:730-757.

Miller, A. H. 1958. Ecologic factors that accelerate formation of races and species of terrestrial vertebrates. Evolution 10: 262-277.

Molino, J. F., and D. Sabatier. 2001. Tree diversity in tropical rain forests: a validation of the intermediate disturbance hypothesis. Science 294:1702-1704.

Nilsson, P. 1991. Surveillance program in the coastal area between Sweden and Norway. Swedish Evironmental Protection Agency Report 3910, Stockholm, Sweden.

Onuf, C. P., J. M. Teal, and I. Valiela. 1977. Interactions of nutrients, plant growth and herbivory in a mangrove ecosystem. Ecology 58:514-526.

Osman, R. W. 1977. The establishment and development of a marine epifaunal community. Ecological Monographs 47:3763.

Paine, R. T. 1966. Food web complexity and species diversity. American Naturalist 100:65-75.

Paine, R. T., and S. A. Levin. 1981. Intertidal landscapes: disturbance and the dynamics of pattern. Ecological Monographs 51:145-178.

Paine, R. T., and R. L. Vadas. 1969. The effects of grazing by sea urchins, Strongylocentrotus spp., on benthic algal populations. Limnology and Oceanography 14:710-719.

Patricio, J., F. Salas, M. A. Pardal, S. E. Jorgensen, and J. C. Marques. 2006. Ecological indicators performance during a re-colonisation field experiment and its compliance with ecosystem theories. Ecological Indicators 6:43-57.

Pavia, H., H. Carr, and P. Aberg. 1999. Habitat and feeding preferences of crustacean mesoherbivores inhabiting the brown seaweed Ascophyllum nodosum (L.) Le Jol. and its epiphytic macroalgae. Journal of Experimental Marine Biology and Ecology 236:15-32.

Petraitis, P. S., R. E. Latham, and R. A. Niesenbaum. 1989. The maintenance of species diversity by disturbance. Quarterly Review of Biology 64:393-418.
Pickett, S. T. A., and P. S. White. 1985. The ecology of natural disturbance and patch dynamics. Academic Press, London, UK

Pollock, M. M., R. J. Naiman, and T. A. Hanley. 1998. Plant species richness in riparian wetlands: a test of biodiversity theory. Ecology 79:94-105.

Rashit, E., and M. Bazin. 1987. Environmental fluctuations, productivity, and species diversity: an experimental study. Microbial Ecology 14:101-112.

Scholes, L., P. H. Warren, and A. P. Beckerman. 2005. The combined effects of energy and disturbance on species richness in protist microcosms. Ecology Letters 8:730-738.

Soderstrom, J. 1996. The significance of observed nutrient concentrations in the discussion about nitrogen and phosphorus as limiting nutrients for the primary carbon flux in coastal water ecosystems. Sarsia 81:81-96.

Sousa, W. P. 1979. Disturbance in marine intertidal boulder fields: the nonequilibrium maintenance of species diversity. Ecology 60:1225-1239.

Sousa, W. P. 1984. The role of disturbance in natural communities. Annual Review of Ecology and Systematics $15: 353-391$

Sousa, W. P. 2001. Natural disturbance and the dynamics of marine benthic communities. Sinauer, Sunderland, Massachusetts, USA.

Stallins, J. A. 2003. Dune plant species diversity and function in two barrier island biogeomorphic systems. Plant Ecology 165:183-196.

Tilman, D. 1980. Resources: a graphical-mechanistic approach to competition and predation. American Naturalist 116:363393.

Tilman, D., and S. Pacala. 1993. The maintenance of species richness in plant communities. University of Chicago Press, Chicago, Illinois, USA.

Tilman, D., D. Wedin, and J. Knops. 1996. Productivity and sustainability influenced by biodiversity in grassland ecosystems. Nature 379:718-720.

Underwood, A. J. 1997. Experiments in ecology: their logical design and interpretation using analysis of variance. Cambridge University Press, Cambridge, UK.

Valdivia, N., A. Heidemann, M. Thiel, M. Molis, and M. Wahl. 2005. Effects of disturbance on the diversity of hard-bottom macrobenthic communities on the coast of Chile. Marine Ecology Progress Series 299:45-54.

Widdicombe, S., and M. C. Austen. 2001. The interaction between physical disturbance and organic enrichment: an important element in structuring benthic communities. Limnology and Oceanography 46:1720-1733.

Wikstrom, S. A., M. B. Steinarsdottir, L. Kautsky, and H. Pavia. 2006. Increased chemical resistance explains low herbivore colonization of introduced seaweed. Oecologia 148:593-601.

Winer, B. J., D. R. Brown, and K. M. Michels. 1991. Statistical principles in experimental design. Third edition. McGrawHill, New York, New York, USA.

Wootton, J. T. 1998. Effects of disturbance on species diversity: a multitrophic perspective. American Naturalist 152:803825.

Worm, B., H. K. Lotze, H. Hillebrand, and U. Sommer. 2002. Consumer versus resource control of species diversity and ecosystem functioning. Nature 417:848-851.

Worm, B., T. B. H. Reusch, and H. K. Lotze. 2000. In situ nutrient enrichment: methods for marine benthic ecology. International Review of Hydrobiology 85:359-375.

Zucchini, W. 2000. An introduction to model selection. Journal of Mathematical Psychology 44:41-61. 